\title{
Tissue Engineering and Regenerative Medicine - New Initiatives for Individual Treatment Offers
}

\author{
Beat M. Frey ${ }^{a}$ Steffen M. Zeisberger ${ }^{b}$ Simon P. Hoerstrup ${ }^{b, c}$ \\ ${ }^{a}$ Blood Transfusion Service Zurich, Zurich-Schlieren, Switzerland; \\ ${ }^{b}$ Wyss Translational Center Zurich, Regenerative Medicine Technologies Platform, University of Zurich and ETH Zurich; Zurich, Switzerland; \\ c Institute for Regenerative Medicine (IREM), University of Zurich, Zurich, Switzerland
}

Tissue engineering (TE) combines the three components - cells, scaffolds and growth factors - to generate tissues for functional replacement of damaged or diseased organs upon transplantation. Further, regenerative medicine (RM) combines TE with other strategies such as cell-based therapies, gene therapy, and immunomodulation, using stem and progenitor cells from various sources in order to induce in vivo organ regeneration [1-3]. TERM, the combination of TE and RM, combines basic sciences such as nanotechnology, biomechanics, bioinformatics, material science, and polymer chemistry with cell biology and medical sciences to promote functional organo(re)genesis. In the light of a growing and aging population with ever increasing demand of organ replacements, TERM might become the appropriate strategy to meet future needs of the patients [4].

Part 1 of the current special topic which was published in the preceding issue of Transfusion MEdicine AND IMMUNOTHERAPY (issue 4, 2016) summarized the use of various stem cell populations such as mesenchymal as well as hematopoiesis- and adipose tissuederived stem cells in the context of tissue regeneration, immune modulation and as transplantation additives [5-7]. In addition, several contributions provided comprehensive reviews on myocardial, cardiovascular and cardiovalvular tissue regeneration [8-10].

The current part 2 of this special topic puts the focus on generation of organ-specific tissues in order to functionally replace damaged organs. Also, regulatory aspects as well as quality issues for clinical application of tissue engineering will be addressed.

The first article by Jessberger et al. [11] summarizes current insights into regenerative capacity of adult brain tissue. Although loss of brain tissue is still associated with functional deficits, the discovery of neurogenic stem cells, their transcription factors and regulators, and of neurogenic niches in the adult brain opens a new view on regenerative potential of the adult brain. However, not only neurogenic differentiation of cells is required for functional brain regeneration, but also the correct integration of induced neu- rogenic cells into the neuromuscular network is a prerequisite for satisfactory results. Given these conditions, appropriate in vivo animal models will be necessary to assess safety and efficacy of neuroregenerative approaches.

The second paper by Smolar et al. [12] deals with impaired bladder function and the potential for corrective intervention by TERM. Since more than two decades, scientists and surgeons have tried to use tissue engineering to replace or complete surgical treatments which often have disappointing outcome. Smolar et al. give a comprehensive overview on the hypes and hopes of the field. However, not only the complex anatomy of the hollow organ creates a challenge to bladder tissue engineering but also its proper innervation and vascularization of the tissue which is a prerequisite for satisfactory functional results. Urine-derived stem cells, mesenchymal and adipose tissue-derived stem cells in combination with various artificial biomaterials and growth factors are the tools for bladder tissue engineering. Unfortunately, despite sophisticated applications of TERM technologies, the generation of properly working bladder tissue is still awaited.

Ruangsawasdi et al. [13] give an intriguing insight into the physiology of site-specific tissue regeneration, presenting experimental work of regenerative endodontology. Infected or necrotic immature teeth often degenerate upon standard treatment. Tissue engineering approaches offer an attractive alternative to conventional treatment options. In a rat model, the authors show convincing data for site-specific pulp-like tissue formation by transplantation of tooth specimens at the calvaria area as opposed to the implantation into the dorsal subcutis. The findings by Ruangsawasdi et al. remind on the observation by Lee et al. [14] showing scarless tendon defect repair by transplantation of in vitro expanded tendon-derived stem/progenitor cells. Obviously, even bradythrophic tissue contains enough residing stem cells with sufficient capacity for tissue-specific regeneration provided the microenvironment is permissive for respective cell proliferation and differentiation.

\section{KARGER}

(๑) 2016 S. Karger GmbH, Freiburg
Dr. Beat M. Frey

Blood Transfusion Service Zurich

Rütistrasse 19

8952 Zurich-Schlieren, Switzerland

bm.frey@zhbsd.ch 
The review by Bhattacharya et al. [15] from the same group focuses on bone tissue regeneration. Bone tissue has a high regenerative capacity for scarless healing of fractures. However, dehiscent bone defects after trauma or tumor resection resist healing and leave behind large bone defects ultimately requiring mutilating surgery. The successful use of bone autografts and cell-free allografts to rescue continuity and induction of new bone formation reflects the extensive regenerative capacity of bone tissue. Bone transplant shortage, transplant infection, and technical restrictions in autologous transplant sample preparation triggered the evaluation of tissue engineering options for bone regeneration. Bhattacharya et al. review the three components which are needed for successful ex vivo bone engineering: scaffolds, cells, and growth factors. Critical aspects of cell-based engineered bone implants such as vascularization, tissue hypoxia, scaffold production, and growth factor combinations as well as clinical hurdles in use of artificial bone implants are addressed.

The concluding two articles focus on regulatory and organizational issues of TERM in order to assure reliant, robust, and reproducible health care services. Hartmannn-Fritsch et al. [16] summarize the relevant conditions, definitions, and practical issues to be considered in fabrication of advanced therapy medicinal products (ATMPs). Their extensive experience in provision of artificial skin replacements allows them to summarize comprehensively the process necessary for clinical grade products and services. In addition regulatory hurdles and commercial conditions for marketing of ATMPs are discussed.
Simeon-Dubach et al. [17] give a view on translating pre-clinical science into clinical applications. According to the authors, about USD 28 billion are spent each year in the USA for non-reproducible research which represents a huge loss of investment and inhibits translation of research towards clinical therapies. They emphasize on the importance to adhere proper quality assurance standards as well as the so-called Biospecimen Reporting for Improved Study Quality (BRISQ) and various quality assurance programs for biobanking such as the Canadian Tissue Repository Network (CTRNet) or College of American Pathologist (CAP) accreditation program. The resources are referenced and may be consulted directly by the interested reader. The authors refer to the National Institutes of Health-proposed roadmap for translation of basic science discoveries into clinical practice and indicate that additional community and public health research may be important for successful translation.

The huge field of TERM can only be tipped on by these two parts of special issue of TMH. Many relevant fields such as scaffold production, bioreactor technology, cell expansion and reprogramming as well as many promising clinical applications of TERM are left behind due to space restriction. However, there are numerous excellent reviews available for each of these topics which the reader is referred to [18-23]. Also, the site of clinical trials (https://clinicaltrials.gov) is a comprehensive repository for ongoing clinical research in tissue engineering and regenerative medicine.

\section{References}

1 Salgado AJ, Oliveira JM, Martins A, Teixeira FG, Silva NA, Neves NM, Sousa N, Reis RL: Tissue engineering and regenerative medicine: past, present, and future. Int Rev Neurobiol 2013;108:1-33.

$\checkmark 2$ Porada CD, Atala AJ, Almeida-Porada G: The hematopoietic system in the context of regenerative medicine. Methods 2015;99:44-61.

3 Lindroos B, Suuronen R, Miettinen S: The potential of adipose stem cells in regenerative medicine. Stem Cell Rev 20117:269-291.

4 US Department of Health and Human Services: 2020: A New Vision - a Future for Regenerative Medicine. Washington, DC, 2005. http://medicine.osu.edu/regenerativemedicine/documents/2020vision.pdf (last accessed September 12, 2016).

5 Müller AM, Huppertz S, Henschler R: Hematopoietic stem cells in regenerative medicine: astray or on the path? Transfus Med Hemother, 2016;43:247-254.

6 Schäfer R, Spohn G, Baer PC: Mesenchymal stem/stromal cells in regenerative medicine: can preconditioning strategies improve therapeutic efficacy? Transfus Med Hemother 2016;43:256-267.

7 Frese L, Dijkman P, Hoerstrup SP: Adipose tissuederived stem cells in regenerative medicine. Transfus Med Hemother 2016;43:268-274

8 Cambria E, Steiger J, Günter J, Bopp A, Wolint P, Hoerstrup SP, Emmert MY: Cardiac regenerative medicine: the potential of new generation of stem cells. Transfus Med Hemother 2016;43:275-281.
Dijkman P, Fioretta E, Frese L, Hoerstrup S: Heart valve replacements with regenerative capacity. Transfus Med Hemother 2016;43:282-290.

$\checkmark 10$ Mallone A, Weber B, Hoerstrup SP: Regenerative medicine - update on cardiovascular regenerative technologies. Transf Med Hemother 2016;43291-296.

11 Jessberger S: Stem cell-mediated regeneration of the adult brain. Transfus Med Hemother 2016;43: DOI: $10.1159 / 000447646$

12 Smolar J, Salemi S, Horst M, Sulser T, Eberli D: Stem cells in functional bladder engineering. Transfus Med Hemother 2016;43: DOI: 10.1159/000447977.

13 Ruangsawasdi N, Zehnder M, Patcas R, Ghayor C, Weber FE: Regenerative dentistry: animal model for regenerative endodontology. Transfus Med Hemother 2016:43: DOI: 10.1159/000447664.

14 Lee CH, Lee FY, Tarafder S, Kao K, Jun Y, Yang G, Mao JJ: Harnessing endogenous stem/progenitor cells for tendon regeneration. J Clin Invest 2015;125:26902701.

15 Bhattacharya I, Ghayor C, Weber FE: The use of adipose tissue-derived progenitors in bone tissue engineering - a review. Transfus Med Hemother 2016;43: DOI: $10.1159 / 000447494$.

16 Hartmann-Fritsch F, Marino D, Reichmann E: About ATMPs, SOPs and GMP: the hurdles to produce novel skin grafts for clinical use. Transfus Med Hemother 2016;43: DOI: $10.1159 / 000447645$.
7 Simeon-Dubach D, Zeisberger SM, Hoerstrup SP: Quality assurance in biobanking for pre-clinical research. Transfus Med Hemother 2016;43: DOI: $10.1159 / 000448254$.

18 Yin X, Mead BE, Safaee H, Langer R, Karp JM, Levy O: Engineering stem cell organoids. Cell Stem Cell 2016; 18:25-38.

19 Wagner Q, Offner D, Idoux-Gillet Y, Saleem I, Somavarapu S, Schwinté P, Benkirane-Jessel N, Keller L: Advanced nanostructured medical device combining mesenchymal cells and VEGF nanoparticles for enhanced engineered tissue vascularization. Nanomedicine (Lond) 2016;11:2419-2430.

20 Nguyen PK, Neofytou E, Rhee JW, Wu JC: Potential strategies to address the major clinical barriers facing stem cell regenerative therapy for cardiovascular disease: a review. JAMA Cardiol 2016; doi: 10.1001/ jamacardio.2016.2750.

21 Mahla RS: Stem cells applications in regenerative medicine and disease therapeutics. Int J Cell Biol 2016; 2016:6940283

22 Kehl D, Weber B, Hoerstrup SP: Bioengineered living cardiac and venous valve replacements: current status and future prospects. Cardiovasc Pathol 2016;25:300305.

23 Emmert M, Cambria E, Steiger J, Günter J, Hoerstrup S: Cardiac stem cell therapy: the next generation. Transfus Med Hemother 2016;43: DOI: 10.1159/000448179. 